\section{CLINICAL PROFILE OF PATIENTS WITH CARPAL TUNNEL SYNDROME}

\section{Sohail Amir ${ }^{\boxplus}$, Maimoona Qadir², Muhammad Usman ${ }^{3}$}

\begin{abstract}
:
OBJECTIVE: To determine the clinical features and demography of patients with carpal tunnel syndrome (CTS).

METHODS: This descriptive cross-sectional study was done on 250 (210 females and 40 males) patients in Neurosurgery Department, Naseer Teaching Hospital, Peshawar from I January 2015 to $31^{\text {st }}$ December 2016. All patients with $\geq$ I clinical feature of median nerve compression at carpal tunnel level were included while patients who underwent any type of intervention of the median nerve at carpal tunnel level and those with known neurological disorder were excluded. Patients were reviewed for epidemiological data including age, gender, symptomatic side, dominance and neurophysiological grades according to American Association of Electrodiagnostic Medication. Data was analyzed by using SPSS version 20.
\end{abstract}

RESULTS: Female to male ratio was 5.2: I. Mean age was $48.5 \pm 2.54$ years in females and $50.5 \pm 5.85$ years in males. CTS was most commonly seen in the age group of $46-60$ years. Bilaterality was seen in 222 (88\%). Mild form of CTS was the most common $(n=126 ; 50.4 \%)$ followed by moderate $(n=120 ; 48 \%)$, severe and very severe in only $1.6 \%$ of patients. Most frequent sensory symptoms observed were paraesthesia in 250 (100\%), weakness in thenar eminence in $230(92 \%)$, nocturnal pain in $225(90 \%)$, pain after physical activity in $212(85 \%)$ cases. Common co-morbidities were diabetes in $80(32 \%)$ and hypothyroidism in 35 (12\%) cases.

CONCLUSION: Predominant age group was 46-60 years with female predominance. Bilaterality with sensory symptoms like paraesthedias, weakness at thenar eminences, nocturnal and daytime pain were commonly observed.

KEY WORDS: Carpal Tunnel Syndrome (MeSH); Demography (MeSH), Entrapment Neuropathy, Carpal Tunnel (MeSH); Nerve Compression Syndromes $(\mathrm{MeSH})$.

THIS ARTICLE MAY BE CITED AS: Amir S, Qadir M, Usman M. Clinical profile of patients with carpal tunnel syndrome. Khyber Med Univ J 2018;10(1):36-39.

\section{INTRODUCTION}

T he commonest form of median nerve entrapment is carpal tunnel syndrome $(\mathrm{CTS})^{1-6}$ and attributes to $90 \%$ of all entrapment neuropathies. It was first described by Paget in 1854, and is defined as a mononeuropathy due to a compressive force distorting the carpal tunnel, ${ }^{9}$ in $3.8 \%$ of the general population. ${ }^{10}$ Incidence is up to 276: 100,000 per year," with a prevalence of $9.2 \%$ in females and $6 \%$ in males ${ }^{12}$ with a peak age incidence of 40 to 60 years. ${ }^{13}$ Factors which contribute in its causation are congenital predisposition, heavy work, injury, fluid retention and the development of any mass lesions in the tunnel. ${ }^{14,15}$

The troublesome features are caused by compression of the median nerve along the carpal tunnel, which is formed on the its three sides by the carpal bones and on the volar surface by the deep transverse carpal ligaments. ${ }^{16}$ Main features of carpal tunnel syndrome include pain in the hand, tingling sensation, numbness in the distribution of the median nerve (thumb, index, middle
$\mathrm{I}^{凶}$ Assistant Professor Neurosurgery, Naseer Teaching Hospital, Peshawar, Pakistan Email:dr.sohailamir@gmail.com Tel: +92-3325723653; +92-3219181303

2 Registrar, Department of Gynecology and Obstetrics Unit B, Khyber Teaching Hospital Peshawar, Pakistan

3 District Specialist, Department of Neurosurgery, Naseer Ullah Babar Memorial Hospital, Peshawar, Pakistan

Date Submitted: February 05, 2017

Date Revised: November 13,2017

Date Accepted: November 23, 2017

finger and the lateral side of the ring finger), ${ }^{17}$ weakness of the grip strength and reduced functional capacity of the affected hand. ${ }^{18}$ Patients are more distressed at night, and complain of clumsiness with activities requiring wrist flexion. ${ }^{19}$ Patients often describe the 'flick sign' in which shaking their wrists relieves symptoms. ${ }^{20}$ Other signs are Tinnel sign, caused by digital percussion to the regions of carpal tunnel and flexor retinaculum, and in Phanel test, there will be paraesthesia in the median nerve innervating area after wrist flexion for $30-120$ seconds. ${ }^{21}$

The nerve conduction study is certainly a diagnostic tool for carpal tunnel syndrome. 22,23 The treatment for carpal tunnel syndrome is either surgical or medical. Surgical treatment is generally recommended for those with severe symptoms, while medical treatments are recommended for those who have mild symptoms or in whom the contraindications limit surgery. ${ }^{24}$ Examples of conservative treatment include oral and injectable steroids, physical therapy, electrotherapy, night splinting and workplace alteration. ${ }^{25}$

The aim of this study was to determine the clinical features and demography of carpal tunnel syndrome cases attending a tertiary care hospital. It emphasizes the health care providers at governmental and non-government level to plan preventive initiatives and management strategies in the light of local and international past and latest scientific research findings and updates.

\section{METHODS}

This descriptive cross-sectional study was conducted at Neurosurgery Department, Naseer Teaching Hospital, 
TABLE I: DEMOGRAPHICAL PROFILE OF PATIENTS WITH CARPAL TUNNEL SYNDROME $(n=250)$

\begin{tabular}{|l|l|c|c|}
\hline \multicolumn{2}{|c|}{ Demographic variables } & Frequency & Percentage \\
\hline \multirow{2}{*}{$\begin{array}{l}\text { Gender } \\
(\mathrm{n}=250)\end{array}$} & Female & 210 & 84 \\
\cline { 2 - 4 } & Male & 40 & 16 \\
\hline \multirow{3}{*}{$\begin{array}{l}\text { Age Group in } \\
\text { years } \\
(\mathrm{n}=250)\end{array}$} & $15-30$ years & 10 & 4 \\
\cline { 2 - 4 } & $31-45$ years & 85 & 34 \\
\cline { 2 - 4 } & $46-60$ years & 93 & 37.2 \\
\cline { 2 - 4 } $\begin{array}{l}\text { Laterality } \\
(n=250)\end{array}$ & $>60$ years & 62 & 24.8 \\
\hline \multirow{3}{*}{} & Bilateral & 222 & 88.8 \\
\cline { 2 - 4 } & Unilateral & 28 & 11.2 \\
\cline { 2 - 4 } & Left & $8 / 28$ & 29 \\
\hline
\end{tabular}

Peshawar from $1^{\text {st }}$ January 2015 to $31^{\text {st }}$ December 2016. Sample size was 250 and sampling technique was consecutive (non-probability) sampling. Approval was obtained from hospital ethical committee. Inclusion criteria were patients with one or more clinical feature of median nerve compression at level of carpal tunnel. Exclusion criteria was patients who have underwent any type of intervention of the median nerve at the carpal tunnel level and those with known neurological disorder.

Patients were reviewed for epidemiological data including age, gender, symptomatic side, dominance, neurophysiological grades i.e. mild, moderate, severe and very severe according to American Association of Electrodiagnostic Medication. The patients were divided into four different age groups I5-30 years, 3I-45 years, 46-60 years and $>60$ years. Neurophysiological grades were defined as:

(a) Mild CTS: prolonged distal sensory peak latency with reduced sensory amplitude

(b) Moderate CTS: abnormal median sensory peak latencies with prolongation of the distal motor latency

(c) Severe CTS: prolonged motor and sensory distal peak latency with absent sensory nerve action potential

(d) Very severe CTS: absent thenar motor or sensory response either with a present or absent lumbrical response ${ }^{26}$

Data was analyzed by using SPSS 20.0 and descriptive analysis was done. Categorical data was analyzed in form of percentages and presented in form of tables.

\section{RESULTS}

A total of 250 patients including 210 females and 40 males were included in the study. A mean age of $48.5 \pm 2.54$ years was found in females and $50.5 \pm 5.85$ years was observed in males. The female to male ratio was $5.2: 1$ and this disorder was most commonly seen in the age group $46-60$ years. Bilaterality of this disorder was seen in 222 (88.8\%) subjects (Table I). Out of 222 patients with bilateral CTS pattern, 192 (86.48\%) were females and 30 (I3.5\%) were males. Similarly, out of 28 unilateral CTS 18 (64.28\%) were

Mild form of CTS was the commonest form noticed in I 26 (50.4\%) of subjects, followed by moderate form (Table II).

Paraesthesia was the most prevalent symptom, being present in 100\% cases followed by weakness at thenar eminances in 230 (92\%), nocturnal pain $225(90 \%)$ and daytime pain in 212 (85\%). Majority of cases had $\geq 1$ symptoms of median nerve compression at the carpal tunnel level as seen in 232 (93\%) patients (Table III).

Co-morbidities were found in form of diabetes which was the most frequent disorder, found in 80 (32\%) cases, followed by hypothyroidism which was observed in 35 (12\%) cases while 3 females and 10 (35.7\%) were males.
( $1.2 \%)$ patients were pregnant.

\section{DISCUSSION}

Carpal tunnel syndrome is the commonest form of mononeuropathy diagnosed on the basis of clinical features and nerve conduction studies. ${ }^{26,27}$ According to a study conducted at London I: 1000 people are diagnosed each year with CTS. ${ }^{28}$

In our study, the higher predominance of CTS is in women with a ratio of 5.2:I which is close to that of other studies where this ratio was observed to be 5.6:1, 5.4:1, 5:I and 4.9:1. ${ }^{16,29-32}$ Saboor A, et al. in their study at Ayub Teaching Hospital, Abbottabad observed that female gender was in predominanace with $86.3 \%$ study population being women. ${ }^{33}$ Mean age of CTS subjects in our study was found to be 48.5 years in females and 50.5 years in males with peak incidence in the age group of 46-60 years. Malibary HM, et al. in their study conducted at Jeddah, Saudi Arabia recruited 336 subjects and observed the mean age in females was 52.4 years and 48.5 years in males. ${ }^{32}$ Likewise Abumunaser LA, et al. in their study concluded the mean age in females to be 45.5 years and 48.5 years in males ${ }^{34}$ which is much closer to our results.

Regarding the laterality, Malibary HM, et al. in 2013 observed that $90.5 \%$ of their patients had bilateral CTS, this figure is observed to be $88.8 \%$ in our study. Similarly, II.2\% of our cases had unilateral CTS whereas it was reported as $9.5 \%$ in the same study. ${ }^{32}$

Paraesthesias was the most prevalent symptom, as it was observed in all of our cases, followed by weakness in thenar eminence which was seen in $92 \%$ of our subjects. These figures were observed as almost same with paraesthesias in all and weakness in same number of subjects by Azevedo JWV, et al. ${ }^{21}$ Likewise sleeping disorder was TABLE II: CATEGORIZATION OF CASES WITH CARPAL TUNNEL SYNDROME $(n=250)$

\begin{tabular}{|l|c|c|}
\hline Category & Frequency & Percentage \\
\hline Mild & 126 & 50.4 \\
\hline Moderate & 120 & 48 \\
\hline Severe & 1 & 0.4 \\
\hline Very severe & 3 & 1.2 \\
\hline Total & 250 & 100 \\
\hline
\end{tabular}


TABLE III: CLINICAL FEATURES OF PATIENTS WITH CARPAL TUNNEL SYNDROME $(n=250)$

\begin{tabular}{|l|c|c|}
\hline Clinical Feature & Frequency & Percentage \\
\hline Paraesthesia & 250 & 100 \\
\hline Weakness in thenar eminence & 230 & 92 \\
\hline Nocturnal pain & 225 & 90 \\
\hline Pain after physical activity & 212 & 85 \\
\hline Radiation of pain to upper limb & 175 & 70 \\
\hline Sleeping disorder secondary to symptoms & 162 & 65 \\
\hline
\end{tabular}

*** Single patient can have more than one clinical feature.

observed in $60 \%$ of their subjects and seen in $65 \%$ of our subjects.

Limitation of our study was confinement to demographic profile with CTS category and pattern. It has the importance in the context of comparing the consistency of our findings with those of other studies, to build a strong evidence of epidemiology, demographic and clinical profile of this disease.

\section{CONCLUSION}

In our study, predominant age group was 46-60 years with female predominance. Bilaterality with sensory symptoms like paraesthedias, weakness at thenar eminences, nocturnal and daytime pain were commonly observed.

\section{REFERENCES}

I. American Academy of Orthopaedic Surgeons. Management of Carpal Tunnel Syndrome Evidence-Based Clinical Practice Guideline. [Cited on: January II, 20I7]. Available from URL: www.aaos.org/ctsguideline. Published February 29, 2016.

2. Amirlak B, Wolff TW, Ahmad O, Upadhyaya KP, Tsai T, Scheker LR, et al. Median Nerve Entrapement. Updated Feb 24, 2016. Internet Communication [Cited on: January II, 2017]. Available from URL: https://emedicine.medscape. com/article/I242387-overview.

3. Padua L, Lo Monaco M, Padua R, Gregori B, Tonali P. Neurophysiological classification of carpal tunnel syndrome: Assessment of 600 symptomatic hands. Ital J Neurol Sci 1997 Jun; | 8(3): | 45-50.

4. Italian Worker's Compensation Authority (INAIL). Annual Report 2000. [Cited on: January II, 20 I7]. Available from URL: http://www. inail.it/cms/ultilingua/inglese/rappor toannuale200 I/RappAnn2000ReIPr eslnglese.pdf.

5. Lo SL, Raskin K, Lester H, Lester B. Carpal tunnel syndrome: a historical perspective. Hand Clin 2002 May; I8(2):2II-7,v.

6. Pfeffer GB, Gelberman RH, Boyes $\mathrm{JH}$, Rydevik B. The history of carpal tunnel syndrome. J Hand Surg $\mathrm{Br}$ I 988 Feb; I 3(I):28-34.

7. Aroori S, Spence RA. Carpal tunnel syndrome. Ulster Med J 2008 Jan;77(I):6-17.

8. Alfonso C, Jann S, Massa R, Torreggiani A. Diagnosis, treatment and follow-up of the carpal tunnel syndrome: A review. Neurol Sci 2010 Jun;3I(3):243-52. DOI: 10.1007/s 10072-009-02 13-9. Epub 2010 Feb 10.

9. Paget J. Lectures on Surgical Pathology. 1854. Lindsay and Blakiston, Philadelphia.

10. Atroshi I, Gummesson C, Johnsson R, Ornstein E, Ranstam J, Rosen I. Prevalence of carpal tunnel syndrome in a general population. J Am Med Assoc $1999 \mathrm{Jul}$ 14;282(2): I53-8.

I I. Mondelli M, Giannini F, Giachhi M. Carpal tunnel syndrome incidence in a general population. Neurology 2002 Jan 22;58(2):289-94.

12. Rask MR. Anterior Interosseous nerve entrapement: (Kiloh-Nevin syndrome) a report of seven cases. Clin Orthop Relat Res 1979 JulAug;(|42): |76-8I.

13.Phallen GS. The carpal-tunnel syndrome. Seventeen years' experience in diagnosis and treatment of six hundred fifty-four hands. J Bone Joint Surg Am 1966 Mar;48(2):2I I-28.
14. National Institute of Neurological Disorders and Stroke (NINDS), Carpel Tunnel Syndrome Fact Sheet. [Cited on: January,2017]. Accessed from: http://www.ninds. nih.gov/disorders/carpel_tunnel/de tail_carpal_tunnel.htm\#68963049.

15. Lam N, Thurston A. Association of obesity, gender, age and occupation with carpal tunnel syndrome. Aust NZJ Surg I 998 Mar;68(3): 190-3.

16. Tay LB, Urkude R, Verma KK. Clinical profile, electrodiagnosis and outcome in patients with carpal tunnel syndrome: a Singapore perspective. Singapore Med J 2006 Dec;47(I2):1049-52.

17. Solomon L, Warwick DJ, Nayagam S. Apley's concise system of orthopaedics and fractures. March 3I, 2005. CRC Press, London. ISBN: 978|444|655I7.

18. Zyluk A, Kosovets L. An assessment of the sympathetic function within the hand in patients with carpal tunnel syndrome. J Hand Surg Eur Vol 2010 Jun;35(5):402-8. DOI: I0.1 I77/I753|9340936/292.

19.Dorwart BB. Carpal tunnel syndrome: A review. Semin Arthritis Rheum 1984 Nov; | 4(2): I 34-40.

20. Krendel DA, Jobsis M, Gaskell PC Jr, Sanders DB. The flick sign in carpal tunnel syndrome. J Neurol Neurosurg Psychiat 1986 Feb;49(2):220-I.

21. de Azevedo JW, de Oliveira AB, Nascimento $\mathrm{Vd}$, de Paiva HR Jr, Viecili L, Rocha MA. Profile of patients on sick leave with carpal tunnel syndrome. Acta Ortop Bras 2015 Sep-Oct;23(5):244-6. DOI: | 0.| 590/|4|3-785220|52305|45 784.

22. Sternbach G. The carpal tunnel syndrome. J Emerg Med 1999 MayJun; I7(3):519-23.

23. Bland JD. Do nerve conduction studies predict the outcome of carpal tunnel decompression? Muscle Nerve 200 I Jul;24(7):935-40.

24.Page MJ, Massy-Westropp N, O'Connor D, Pitt V. Splinting for carpal tunnel syndrome. Cochrane 
Database Syst Rev $2012 \mathrm{Jul}$ II;(7):CD0I0003. DOI: 10.1002/ |465| 858.CD010003.

25. Huisstede BM, Hoogvliet $P$, Randsdorp MS, Glerum S, van Middelkoop M, Koes BW. Carpal tunnel syndrome. Part I: effectiveness of nonsurgical treatments -- a systemic review. Arch Phys Med Rehabil 2010 Jul;9I(7):98I-1004. DOI: I0.1016/j.apmr.20I0.03.022.

26. Rempel D, Evanoff B, Amadio PC, de Krom M, Franklin G, Franzblau A, et al. Consensus criteria for the classification of carpal tunnel syndrome in epidemiologic studies. A m J Public $\mathrm{Health}$ |998;88(I0):|447-5 |.

27. Bland JD. Carpel tunnel syndrome. Br Med J 2007 Aug;335(76 I 5):343-6.
28. McCornick A, Fleming D, Charlton J. Morbidity statistics from general practice: Fourth National Study 1991-1992. London: H.M.S.O; 1995. Print.

29. Chacko JP, Chand RP, Bulusu S, Tharakan JJ. Clinical profile of carpal tunnel syndrome in Oman. Neurosciences (Riyadh) 2000 Oct;5(4):223-5.

30. Bahou YG. Carpal tunnel syndrome: A series observed at Jordan University Hospital (JUH), June 1999- December 2000. Clin Neurol Neurosurg 2002 Jan; I 04(I):49-53.

31. Al-Suleiman AA, Ismail HM. Carpal tunnel syndrome: A clinical and electrophysiological study of 220 consecutive cases at King Fahd Hospital of the University, Al-Khobar.
Saudi Med J I 997; I8(I):59-63.

32. Malibary HM, Al-Najjar AT, Yassen DM, Abuhussain HAA, Radhwi OO, Alfares ZR. Clinical profile of carpal tunnel syndrome in a teaching hospital. Pak J Med Sci 2013 Jan;29(I):II9-2I. DOI: I0.12669/ pjms.29l.2946.

33. Awan AS, Khan A, Afridi SA, Khan IU, Bhatti SN, Ahmed E, et al. Early response of local steroid injection versus mini incision technique in treatment of carpal tunnel syndrome. J Ayub Med Coll A b bot abad $2015 \mathrm{~J}$ a n Mar;27(I):192-6.

34.Abumunaser LA. Demographic pattern of carpal tunnel syndrome in western Saudi Arabia. Neuroscience (Riyadh) 2012 Jan; $17(1): 44-7$.

\section{AUTHOR'S CONTRIBUTION}

Following authors have made substantial contributions to the manuscript as under:

SA: Concept \& study design, acquisition, analysis \& interpretation of data, final approval of the version to be published.

MQ: Analysis \& interpretation of data, drafting the manuscript, critical review, final approval of the version to be published.

MU: Drafting the manuscript, critical review, final approval of the version to be published.

Authors agree to be accountable for all aspects of the work in ensuring that questions related to the accuracy or integrity of any part of the work are appropriately investigated and resolved. 